\title{
Cooperative learning approach in Engineering Physics Course
}

\author{
S. N. Pusawale ${ }^{\text {ab }}$ \\ a. Department of Sciences \& Humanities, Rajarambapu Institute of Technology, Rajaramnagar, Sangli, Maharashtra, India \\ b.Shivaji University, Kolhapur, Maharashtra, India \\ swati.pusawale@ritindia.edu
}

\begin{abstract}
The paper presents the use of cooperative learning incorporation in Engineering Physics course by using Jigsaw methodology for first year engineering students. Engineering Physics is the fundamental course and the fundamentals of this course are directly applicable in the majority branches of engineering. Therefore, a good understanding of this course is highly essential for better learning in higher classes. However, this is also one course which students find difficult to learn. In this regard, we observed that instead of traditional teaching methodology there is a need for implementing active learning methodologies for meaningful learning. The jigsaw technique is useful for self as well as peer learning, through the division of tasks among the students. The purpose of this study is to investigate the effects of this technique on the learning of students. It was observed that with the implementation of the jigsaw technique it increased student's participation in classroom activities as well as they become considerate for self as well as their peers learning. In accordance with this the results obtained in terms of feedback and marks, we observed that this technique is more effective than the conventional teaching methods.
\end{abstract}

Keywords: Engineering Physics, Active Learning, Jigsaw technique, Course attainment

\section{Corresponding Author}

Dr. Swati N. Pusawale, Department of Sciences \& Humanities, Rajarambapu Institute of Technology, Rajaramnagar, Sangli, Maharashtra, India.

swati.pusawale@ritindia.edu

\section{Introduction}

Over past few years of the engineering education system in India is evolving rapidly with a major change in curriculum, teaching and assessment methodologies. The education system is more outcomes based nowadays. In the four years of engineering student learns different courses.
Especially first-year engineering students learn courses from science, engineering, humanities, and social science background. Among all these courses, Engineering Physics course attempts to explore the ways of working of nature and presents mankind, the new facts, their interpretation in the form of theories and a host of physical discoveries and, it is the engineer who has to use these advances in science for the betterment of life [1]. Therefore we need engineers whose learning in Physics should be clear and as a Course teacher, we should discover the different ways through which this is possible.

It has been already proved by many of the educational scientists that traditional teaching methodologies cannot take whole responsibilities of learning and there is a major need for activity based teaching methodologies. The advantage of active teaching methodology is that it is more students centric. As we are aware every graduate is required to have a certain skill set such as knowledge, teamwork, leadership, etc. and in order to enhance these skills, active teaching methods work effectively compared to traditional teaching.

Among the different active teaching methods, Jigsaw technique is a research-based cooperative learning technique invented and developed in the early 1970s by Elliot Aronson and his students at the University of Texas and the University of California [2]. This is a group activity in which the students learns through the material provided and discuss on particular topic or concept while keeping in mind the fact that they have to teach or explain it to their colleagues. This technique is very popular as it ensures the teamwork; group learning and most importantly it makes students responsible for their own learning as well as learning of their peers many academicians have used this technique and got better results in the learning of students compared with traditional teaching methodologies [3-13].

In this paper we are describing the way this activity was carried out for Engineering Physics course and what impact it made on the learning of students through the feedback conducted and attainment of course outcomes

\section{Methodology}


The jigsaw method is applied in the class of F. Y. B. Tech for the topic Laser, Fibre Optics and Optoelectronic devices. The total strength of the class was 65 . The following steps are followed for execution of this method

i) The class is divided into a group of 5-6 students based on gender and earlier performance. This way 10 groups are made of each 6 group members and one group is made with 5 members. Thus the totals of 11 groups are made. These 11 groups are assigned as home groups.

ii) After the formation of home group one leader is selected from each group, the leader is for smooth conduction of the activity and monitoring the performance of the group members, and keeping them on track.

iii) After the formation of the home group, the content of the particular topic is divided into segments according to the size of the group. For 6 members group, the topic is divided into 6 segments and for 5 member group, the topic is divided into 5 segments.

iv) Each student of the home group is assigned a particular segment of the topic.

v) Sufficient time is given to the students to read their segment and become familiar with it.

vi) Temporary expert groups are formed by having one student from each group; those are assigned with the same segment. Sufficient time was given to students in the expert group to discuss the main part of their segment

vii) Students are then sent back to their home group.

viii) Each student of the group is asked to present his/her segment in their home group. The group members are encouraged to ask doubts.

ix) During this presentation, instructor monitored the overall process and clarified the doubts raised by each group.

x) An assignment in the form of group presentation and written test is conducted at the last.

The overall steps of Jigsaw method are shown in Fig.1

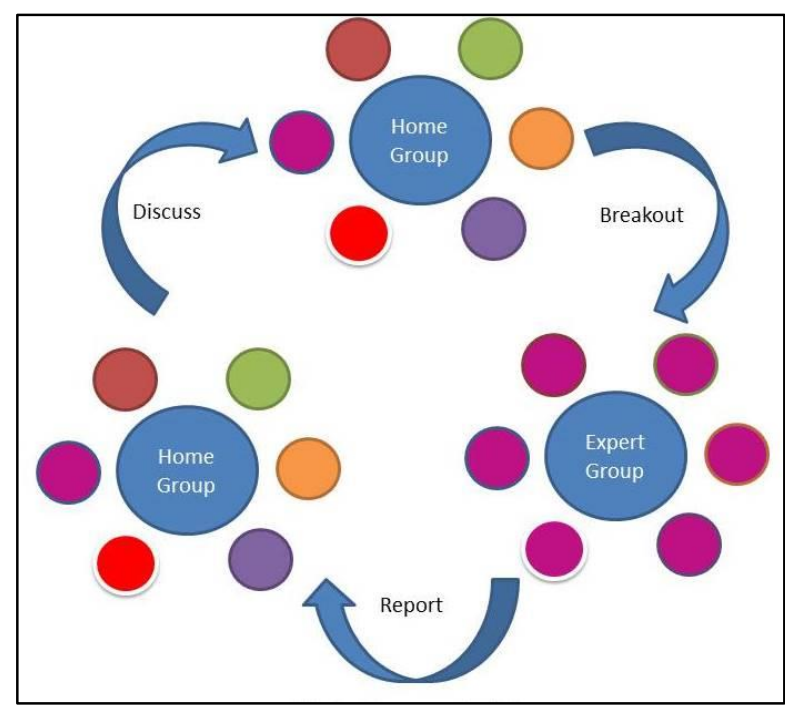

Fig.1 Jigsaw methodology

\section{Result}

In order to know the effect of the applied technique on the students learning, feedback had been taken in the form of questions and ratings. For conducting feedback we used online Monkey survey application, where the student can register their response anonymously. The total of 62 students has registered their response to this activity. The questions asked and the response by students is discussed below.

We asked students to rate the jigsaw active technique; the response we got is shown below in Fig. 2

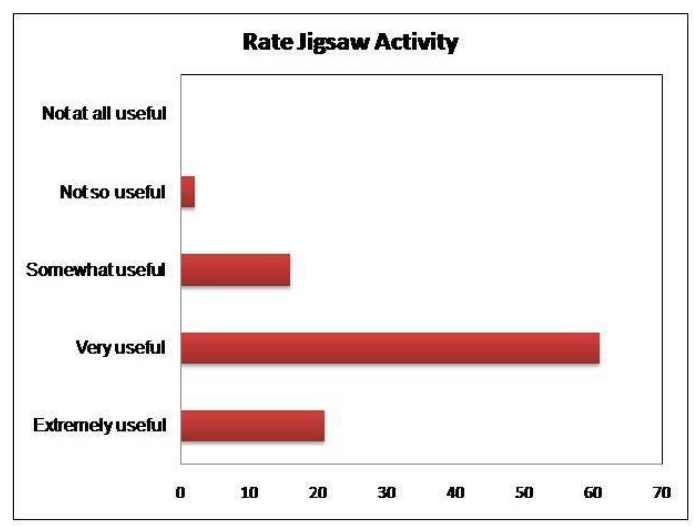

Fig. 2 Feedback given by students for Jigsaw activity

Majority of the students ( $82 \%$ ) found the activity extremely useful in learning. Fig. 3 shows the response of students to the question asked about how this activity helped you to realize the importance of skills of proper planning, creativity, and participation. 


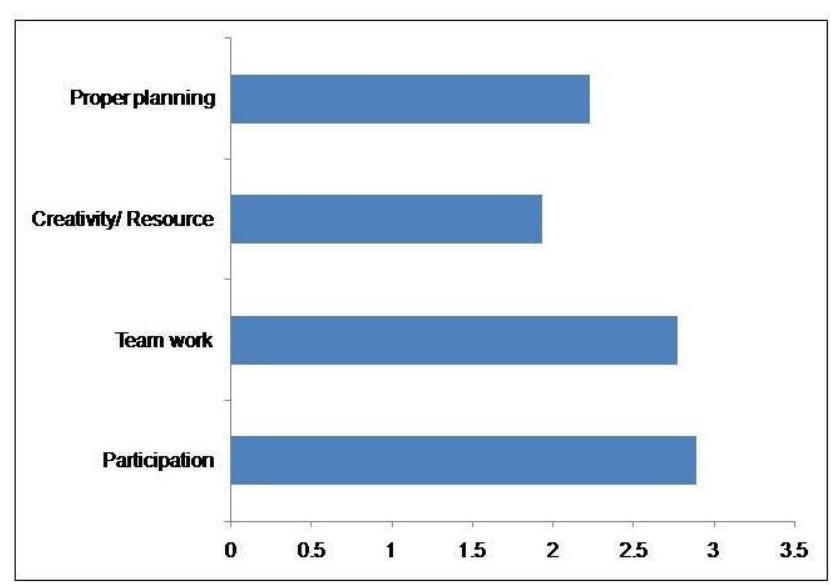

Fig. 3 Feedback given by students

The more rating had been registered for participation and proper planning. Slightly less rating had been given to creativity and resource preparation but this can be understood as creativity is a high-level skill and for firstyear students this will be slightly difficult to achieve.

Fig. 4 shows the response to the question that does the student prefer the jigsaw activity over the traditional teaching styles. Most of the students not only agreed that they prefer such activity over traditional teaching methodology but they also demanded that such kind of activities should be incorporated as and whenever necessary for better class engagement. Some of the students also responded that due to this activity they took ownership of their learning as well as learning of their peers as this is cooperative learning method.

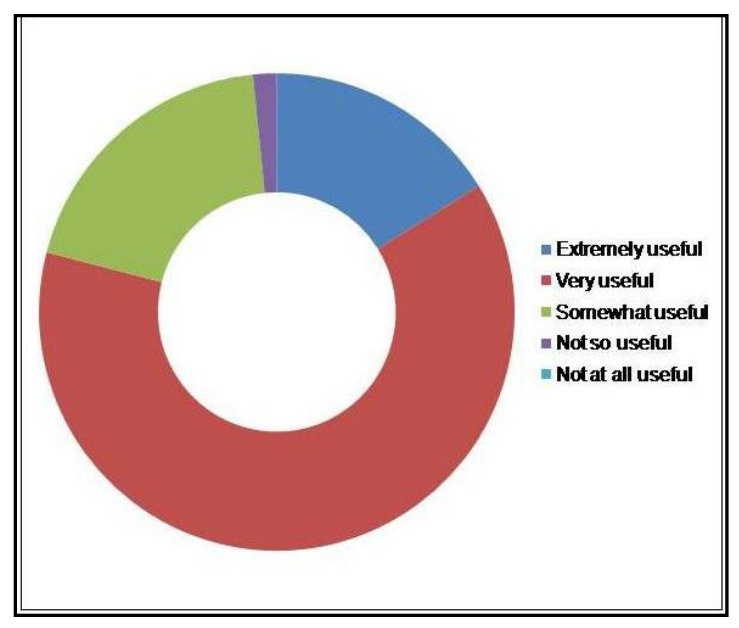

Fig. 4 Feedback given by students

In order to know the students' performance in the test, we have considered course attainment. There are a total of sixtopics each with particular course outcome from $\mathrm{CO} 1$ to CO6 respectively. For this particular topic, we have course outcome no. 4 i.e. $\mathrm{CO} 4$. The comparison for $\mathrm{CO}$ attainment is shown below. For attainment calculation, we had used IonCudos software available at RIT Islampur.

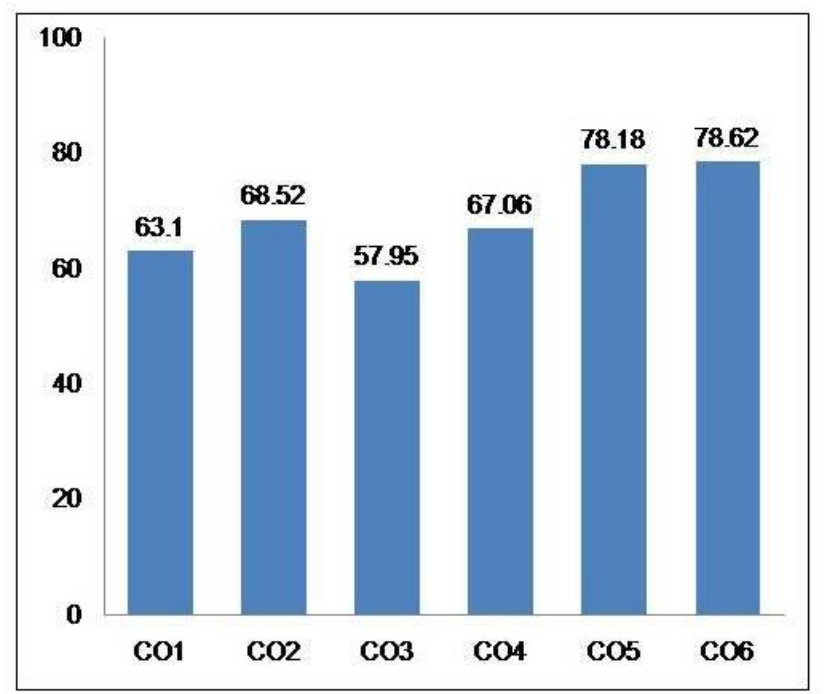

Fig. $5 \mathrm{CO}$ attainment of Course

From the $\mathrm{CO}$ attainment comparison we observed that the maximum attainment $78.18 \%$ and $78.62 \%$ is observed for $\mathrm{CO} 5$ and $\mathrm{CO} 6$ which are related to topic no. 5 and 6 respectively. The reason why the attainment is larger is that these two topics carry more weightage in the end semester examination and students always pay more attention to these topics to score more. Now focussing on the rest of the course outcomes $\mathrm{CO} 2$ is having attainment $68.52 \%$ but for this topic, we have conducted a group problem-solving technique which might help better to attain the questions. Now from remaining $\mathrm{COs}$ the concerned $\mathrm{CO}$ for this activity is $\mathrm{CO} 4$ with the attainment of $67.06 \%$ and this is the fourth highest among all COs. Definitely the attainment of $\mathrm{CO} 4$ is higher than the $\mathrm{CO} 1$ and $\mathrm{CO} 3$ where the topics were taught by using traditional teaching methodology. Although we are not claiming the whole credit is for the jigsaw activity for higher attainment as there are other parameters too that can affect $\mathrm{CO}$ attainment, but we do believe there is some positive impact of this activity on the performance of the students which they too admitted through feedback. Thus the activity had a positive impact on $\mathrm{CO}$ attainment as well as learning of students. Due to lack of time we are not able to conduct any different activity as Jigsaw itself require sufficient lecture hours to learn a topic. Therefore we have not made in comparison of this activity with other active learning methods but in future we will definitely plan Jigsaw and other activities for course so we will be able to compare the results between different teaching methodologies.

\section{Conclusions}

The Jigsaw active learning is successfully implemented in the First year engineering class. The activity managed to achieve the important goal of learning as well as developed certain skills within the students such as teamwork, leadership and making them responsible for their own and peers learning. As the $\mathrm{CO}$ attainment for this particular topic by this method is not very large but still this activity 
has raised awareness about active learning and the importance of different soft skills within students. We observed increased interaction of students with course teacher and among themselves too by using this activity. Incorporating such activities at First-year level will surely increase the bonding between student-student and student teacher and will make them confident in the process of learning.

\section{References}

1. Rao. A. P. (1994) Role of Physics in engineering Education, Journal of engineering education and transformations, 8 (2), 43-47.

2. www.jigsaw.org, last visited on $9^{\text {th }}$ September 2019.

3. Dhage J. R., Patil M. S., Pawar A. B. (2017) Implementation and Feedback Analysis of Jigsaw Active Learning Method, Journal of Engineering Education Transformations, 30 (3) 192-199.

4. Juweto G.A. (2015, Effects of Jigsaw Co-Operative Teaching/Learning Strategy and $\backslash$ School Location on Students Achievement and Attitude towards Biology in Secondary Schoolin Delta State", International Journal of Education and Research, 3(8), 31-40

5. Adhami M., Marzban A. (2014) The Effect of Jigsaw Task on Reading Ability of Iranian Intermediate High School EFL Learners, Journal of Academic And Applied Studies, 4(2), 13-24

6. Göçer A. (2010) A comparative research on the effectivity of cooperative learning method and jigsaw technique on teaching literary genres, Educational Research and Reviews, 5 (8), 439-445.

7. Rambabu M., Ramana N., Sadanandam M. (2018) An Active and Collaborative Learning Practice through Mind Mapping Using Jigsaw Activity of Class Room Based Interaction in Engineering Education, Journal of Engineering Education Transformations [S.I.], Jan 2018, ISSN 2394-1707, doi:10.16920/jeet/2018/v0i0/120934.

8. Sadler D. R. (1998) Formative assessment: revisiting the territory. Assessment in Education, 5(1), 77-84.

9. Anderson, Frances, Palmer J., Jesse (1988) The jigsaw approach: students motivating students, Education, 109(1) 59-62.

10. Azmin N. (2016) Effect of the Jigsaw-Based Cooperative Learning Method on Student Performance in The General Certificate of Education Advanced-Level Psychology: An Exploratory Brunei Case Study, International Education Studies, 9(1), ISSN 1913.

11. Dat T. (2016) The Effects of Jigsaw Learning on Students' Knowledge Retention in Vietnamese Higher Education, International Journal of Higher Education, 5(2), 236253.

12. Arra C. T, D'Antonio M. D., D’Antonio Jr., M. (2011) Students' Preferences for Cooperative Learning Instructional Approaches: Considerations for College Teachers, Journal of Research in Education, 21(1), 114-126.
13. Coffman S. J. (2003) Ten Strategies for Getting Students to Take Responsibility for their Learning, College Teaching, 51(1), 2-4. 